\title{
A universal monoclonal antibody protects against all influenza $A$ and $B$ viruses by targeting a highly conserved epitope in the viral neuraminidase
}

\author{
Tracey M Doyle ${ }^{1,2}$, Anwar M Hashem ${ }^{1,3,4}$, Changgui Li ${ }^{5}$, Doris J Bucher ${ }^{6}$, Gary Van Domselaar ${ }^{7}$, Junzhi Wang ${ }^{5}$, \\ Terry Cyr ${ }^{1}$, Aaron Farnsworth ${ }^{1}$, Runtao He ${ }^{7}$, Aeron C Hurt ${ }^{8}$, Earl G Brown ${ }^{2,9}$, Xuguang Li $i^{1,2,9^{*}}$
}

From 2nd International Genomic Medical Conference (IGMC 2013)

Jeddah, Kingdom of Saudi Arabia. 24-27 November 2013

\section{Background}

Hemagglutinin (HA) and neuraminidase (NA) are the two major surface glycoproteins of influenza viruses and the main targets of vaccine-induced antibodies (Abs). While several broadly neutralizing Abs targeting conserved epitopes in diverse HA subtypes have been isolated, NA-specific Abs could only cross-protect partially against homologous and heterologous strains from the same subtype.

\section{Materials and methods}

Comprehensive bioinformatics analyses of all publicly available full-length NA sequences using multiple alignments and Shannon entropy were conducted to identify conserved sequences in all influenza A and B viral NA [1]. Growth kinetics of wild-type or recombinant viruses with single alanine substitutions within the identified regions was then analyzed in MDCK cells. A rabbit monoclonal $\mathrm{Ab}(\mathrm{mAb})$, denoted as HCA-2, raised against one of the characterized sequences was then examined for its in vitro inhibitory effects and in vivo prophylactic efficacy against several influenza A and B strains.

\section{Results}

Bioinformatics analyses uncovered a universally conserved 9-mer peptide amongst all influenza NA proteins (amino acids 222-230 and comprised of "ILRTQESEC"). Substitutions within this universal epitope underscored its crucial roles in viral fitness and replication [2]. Importantly, the HCA-2 mAb showed broad in vitro

\footnotetext{
* Correspondence: Sean.Li@hc-sc.gc.ca

${ }^{1}$ Centre for Vaccine Evaluation, Biologics and Genetic Therapies Directorate, HPFB, Health Canada, Ottawa, ON, Canada

Full list of author information is available at the end of the article
}

inhibition against multiple strains from all influenza A NA subtypes (N1-N9) and influenza B viruses from both Victoria and Yamagata genetic lineages [3,4]. It also provided heterosubtypic protection in mice against lethal doses of H1N1 and H3N2 strains. Finally, amino acid residues I222 and E227, located in close proximity to the active site, were found to be indispensable for inhibition by this $\mathrm{mAb}[3,4]$.

\section{Conclusions}

These findings reveal the essential role of this unique highly-conserved sequence in NA function and viral replication and indicate that it is sufficiently exposed to allow access by inhibitory antibody during the course of infection. Thus, it could represent a potential target for novel antivirals or targeted-vaccines against diverse strains of influenza A and B viruses.

\begin{abstract}
Authors' details
${ }^{1}$ Centre for Vaccine Evaluation, Biologics and Genetic Therapies Directorate, HPFB, Health Canada, Ottawa, ON, Canada. ${ }^{2}$ Department of Biochemistry, Microbiology and Immunology, University of Ottawa, Ottawa, ON, Canada. ${ }^{3}$ Department of Medical Microbiology and Parasitology, Faculty of Medicine, King Abdulaziz University, Jeddah, Saudi Arabia. ${ }^{4}$ Special Infectious Agents Unit, King Fahd Medical Research Centre, King Abdulaziz University, Jeddah, Saudi Arabia. ${ }^{5}$ National Institutes for Food and Drug Control, Beijing, China. ${ }^{6}$ Department of Microbiology \& Immunology, New York Medical College, Valhalla, NY 10595, USA. ${ }^{7}$ National Microbiology Laboratory, Public Health Agency of Canada, Winnipeg, MB, Canada. ${ }^{8}$ WHO Collaborating Centre for Reference and Research on Influenza, 10 Wreckyn St., North Melbourne, Victoria 3051, Australia. ${ }^{9}$ Emerging Pathogens Research Centre, University of Ottawa, Ottawa, ON, Canada.
\end{abstract}

Published: 2 April 2014

References

1. Gravel C, Li C, Wang J, Hashem AM, Jaentschke B, Xu KW, Lorbetskie B, Gingras G, Aubin Y, Van Domselaar G, Girard M, He R, Li X: Qualitative and 
quantitative analyses of virtually all subtypes of influenza $A$ and $B$ viral mneuraminidases using antibodies targeting the universally conserved sequences. Vaccine 2010, 28(36):5774-5784.

2. Doyle TM, Jaentschke B, Van Domselaar G, Hashem AM, Farnsworth A, Forbes NE, Li C, Wang J, He R, Brown EG, Li X: The universal epitope of influenza $A$ viral neuraminidase fundamentally contributes to enzyme activity and viral replication. J Biol Chem 2013, 288(25):18283-18289.

3. Doyle TM, Hashem AM, Li C, Van Domselaar G, Larocque L, Wang J, Smith D, Cyr T, Farnsworth A, He R, Hurt AC, Brown EG, Li X: Universal antineuraminidase antibody inhibiting all influenza $A$ subtypes. Antiviral Res 2013, 100(2):567-574.

4. Doyle TM, Li C, Bucher DJ, Hashem AM, Van Domselaar G, Wang J, Farnsworth A, She Y-M, Cyr T, He R, Brown EG, Hurt AC, Li X: A monoclonal antibody targeting a highly conserved epitope in influenza $B$ neuraminidase provides protection against drug resistant strains. Biochem Biophys Res Commun 2013, 441(1):226-229.

doi:10.1186/1471-2164-15-S2-P8

Cite this article as: Doyle et al: A universal monoclonal antibody protects against all influenza $A$ and $B$ viruses by targeting a highly conserved epitope in the viral neuraminidase. BMC Genomics 2014 15(Suppl 2):P8.

\section{Submit your next manuscript to BioMed Central} and take full advantage of:

- Convenient online submission

- Thorough peer review

- No space constraints or color figure charges

- Immediate publication on acceptance

- Inclusion in PubMed, CAS, Scopus and Google Scholar

- Research which is freely available for redistribution

Submit your manuscript at www.biomedcentral.com/submit
Ciomed Central 